\title{
Factors Affecting the Mental Well-Being of Undergraduate Students in Karachi
}

\author{
Zeenat Ismail \\ Professor of Psychology \\ Department of Social Sciences and Liberal Arts \\ Institute of Business Administration, Karachi \\ Neshmia Shujaat \\ Department of Social Sciences and Liberal Arts \\ Institute of Business Administration, Karachi
}

\begin{abstract}
This study explores the relationship of five variables commonly associated with mental wellbeing. The variables include perceived social support, family demands, socioeconomic status, gender and educational background. Mental well-being comprises of two subcomponents i.e. stress and depression and poor mental well-being is indicated by high scores on stress and depression and vice versa. The study further examines any significant associations the five variables have with one another. 208 undergraduate students from various universities across Karachi voluntarily responded to an online questionnaire. In agreement with our hypotheses, Pearson's coefficient correlations showed all five variables had a significant relationship with mental well-being. However, the interrelations among the five variables were contrary to our predictions. Independent $T$ tests revealed that males $(M=20.45, S D=3.22, t(206)$ = 6.92) compared to females $(M=16.92, S D=4.09)$ perceived greater social support, especially from their friends. Females $(M=17.54, S D=4.84)$ experienced greater family demands than males $(M=14.92, S D=3.70)$. Females also reported higher scores on depression $(M=14.37, S D=6.45)$ with a moderate effect size (eta squared=0.06), thereby suggesting a link between family demands and depression. Students from higher socioeconomic groups and non-mainstream educational backgrounds like the social sciences reported greater scores on stress and depression.
\end{abstract}

Keywords: Mental Well-Being, Perceived Social Support, Family Demands, Stress, Depression.

\section{INTRODUCTION}

Adolescence is an important phase in the development of human beings. Individuals at this precarious stage of their lives undergo novel experiences and several identity formation crises that leave their mental health pre-exposed to psychological issues like stress and depression. Stress is defined as the individual's perception of such demands being placed on them that exceed the individual's current resources to tackle them [2]. Depression on the other hand, is one of the most common mental disorders and is characterized by a deep sense of sadness, hopelessness, loneliness and low self-esteem [1]. Students that report depressive symptoms demonstrate poor learning abilities and achieve lower grades at school [27]. Approximately 20 to 25 percent of individuals experience depression at some point in their lives [23]. Although the disorder is a rarity in childhood, its chances increase substantially as adolescence approaches.

Several studies on adolescent students show that the prevalence of depression has strong and positive correlation with chronic stress. The two psychological constructs also serve as major indicators of our mental health. In this vein, mental well-being has been studied in terms of 
how stress and depression correlate with certain common social variables. For example, student mental health has often been examined in relation to perceived social support. Social support is defined as the care or help provided by others that can be readily felt, noticed and accepted by an individual [29]. It is the perception of being valued by a social network that can be called upon in times of need [15]. Across most cultures, the perception of social support from family members, friends or a spouse act as a buffer against stress and promote overall mental health [14]. However, some students experience more demands than support from their family. Family demands are the perceptions by students that their families unrealistically pin their hopes on them and burden them with requests and desires that they may not be able to fulfil [15]. The quality of social support provided or the extent of demands placed upon the student depend on factors like the students' gender, their academic background, the support network's socio-economic status or the overall cultural background that dictates the nature of their relationship.

Such nuances in experience are often neglected in studies assessing the mental health of students. This study aims to investigate the interactive role of these factors that affect mental well-being in undergraduate students. They are discussed at length in the literature review below.

\section{Stress in Adolescents}

\section{LITERATURE REVIEW}

Students often represent a society's investment in its future [18]. Therefore, issues surrounding mental wellness are increasingly being investigated upon the student population. Higher education is a competitive environment that is characteristic of a demanding and time challenging routine. This leaves many students exposed to high levels of stress [24]. The pressure to achieve at school and college can become potent stressors for adolescents. Kumaraswamy [18] focuses particularly on stress in undergraduate students and contends that there are numerous sources of stress in their lives. He postulates that when students appraise their education as a challenge, they tend to see it more as threat that must be conquered or battled with [18]. Henceforth, stress often arises due to the perception of the event as stressful, rather than the event per se [10]. It affects one's mental well-being when an appropriate response to an event is deemed necessary but the resources to do so are not available [10]. Stress is explained via two models of social support; the direct effects hypothesis and the stress buffering hypotheses [10]. The stress buffering hypothesis asserts that social support is beneficial in suppressing the effects of stress when it occurs. The direct effects hypothesis on the other hand, posits that the perception of social support is beneficial all round i.e. it promotes good health and molds resilient individuals regardless of their experience with stress. Thus, a reliable social support system in the form of family, friends and colleagues can assuage the intensity of stressful events.

\section{Depression}

The occurrence of depressive symptoms in students is a recurrent theme in contemporary literature. The prevalence of depression in university students is around 20 to 32 percent which includes the risk of suicide, substance abuse, low self-esteem and poor performance in academia [23]. The results from Ramezkhani et al's [23] cross-cultural research on mental well-being showed that social support played a significant moderating role in alleviating stress-inducing factors and shielding from depression. Similarly, Bukhari's [4] research on university students in Karachi also illustrates that perceived social support is negatively associated with depression, anxiety and stress. The results showed that depression rates plummeted from $58 \%$ to $6 \%$ when there was a strong perception of social support [4]. 
Although a causal relationship is difficult to determine between stress and depression, there are several studies that affirm a strong correlation between the two. For example, Sokratous et al [26] found that university students who reported high number of stressful life events were likely to exhibit clinical depressive symptoms. Another study on undergraduate students in China found that those experiencing high levels of stress were more likely to develop depressive symptoms [30]. Particularly, students who belonged to strong social support groups reported lower levels of stress and were therefore less likely to develop depression [30]. A similar study was conducted in Lahore, Pakistan by Jibeen [14] to confirm these findings. 912 undergraduate students from COMSATS Institute of Information Technology participated in the study on the relationship between social support and psychological wellbeing. Students experiencing low levels of family and peer support were prone to stress and depression. According to Jibeen, perceived social support is considered a significant negative predictor of depression and low levels of social support substantially affect students from collectivist cultures [14].

\section{Social Support}

Social support provides the encouragement, care and direction needed by the adolescent to overcome adverse circumstances. Hamdan-Mansour \& Dawani examined the link between social support and stress among university students in Jordan [11]. Their results indicated that there is a negative correlation between perceived stress and perceived social support, thereby confirming the copious amounts of research that proposes the importance of social support for greater mental health. Miething, Almquist, Östberg, Rostila, Edling, \& Rydgren, examined the role of social support networks outside the home to mitigate stress in students [20]. They posited that friendship networks play a crucial role in helping individuals cope with the increasing stress, especially when individuals feel they cannot rely on their family members for emotional support. Meithing et al's study showed that the quality of friendship networks established in late adolescence transfer into young adulthood better psychological well-being [20]. However, they also learnt that the strength of friendship networks wanes with age, suggesting that perhaps social support is then sought outside the friend circle in adults.

\section{Family Demands}

Deb, Strodl \& Sun [8] carried out a research with high school students in Kolkata and discovered that 66 per cent of the participants admitted to feeling pressure and demands from their parents concerning their academic performance. The results of their study indicated a positive relationship between academic stress and parental pressure. Likewise, Khallad and Jabr [15] conducted a comprehensive cross-cultural study to illustrate the impact of family demands and perceived social support on the mental well-being of Jordanian and Turkish college students. The Jordanian students were living with their families while the Turkish students had immigrated to Jordan for higher education and were living in hostels. The results from their study indicated that Jordanians relied more on their families for social support since they belonged to a collectivist culture. Turkish students relied more on their friends for social support as they lived away from their families. In addition to this, students who perceived their families to be demanding reported poorer mental health with significantly higher scores on depression. Meithing et al's study suggests that stress and other psychological issues mainly arise from the series of changes in the individual's environment such as leaving the comfort of the parent's home and establishing an identity outside of it for pursuit of higher education or job prospects [20]. The shifting social contexts places a strain on these young adults as they encounter greater demands and expectations from their families. 


\section{Gender Differences}

Gender is often considered an important variable when dealing with the mental well-being of young adults, especially because males and females tend to form distinct social support patterns [2]. For example, Hamdan-Mansour \& Dawani's study found that Jordanian females experienced greater stress levels than Jordanian males despite reporting greater social support [11]. An explanation offered for this gender difference was the socialization of women in Jordanian culture. Families tend to be more protective of females in Jordan but even when their mobility is restricted females find it easier to actively seek help from their friends than males do. Males may find it difficult to express their troubles to their friends and even family members. Likewise, Tam, Foo, \& Lee [26] discovered that Malaysian females perceived greater social support from friends and family members. However, there was no significant difference in the mental health status of males and females. In this vein, Kania [16] investigated gender differences in the experience of stress and found no statistically significant differences in their mean scores. Her study was geared towards establishing a biological difference in stress perception and she argued that neither males nor females are naturally pre-exposed to stress. Khallad \& Jabr's [15] cross cultural study showed that stress was more prevalent in their Jordanian female participants only, suggesting that differential treatment of the genders can explain patterns of mental well-being.

\section{Mental Health's Relation to Educational Background}

A large majority of well-being studies are now oriented towards medical students since it is believed that they are exposed to a more stressful, rigorous and time-challenging routine. Rehman, Habib \& Fatima [24] attempted to understand the significance of social well-being in the medical student population of Karachi. The objective of their study was to investigate if maintaining strong social networks and social support systems helps combat stressful conditions and protects against various physiological and psychological illnesses. The results showed that the majority of female participants displayed better psychosocial well-being than males since they had better social connectivity with their friends and family [24]. Some literature posits that within academia, the stress experienced by medical students is far greater than the stress experienced by other students [4]. A systematic review of the mental well-being issues in medical students across Asia bolstered support for this claim that certain sub populations of medicine students were more prone to mental health issues [7]. The review also illustrated that home staying medical students showed a $12.1 \%$ chance of developing depression compared to $9.2 \%$ of hostel stayers. In other words, home-staying medical students are 1.33 times more likely to develop depression compared to hostel-stayers [7].

However, a point to be kept in mind is that there has been little research conducted on the mental well-being or psychological health of students from other educational backgrounds. A rare attempt to assess stress in terms of academic background was made by [28]. They divided their sample into pure science and applied science undergraduate students, where pure science students included those pursuing training in physics, math and chemistry while applied science students included those pursuing training in computer sciences, information technology and engineering. Their study found a statistically significant difference in the stress levels of the two groups; applied science students were more stressed than pure science students.

\section{Socioeconomic Status}

Hudson's [12] longitudinal study across the state of Massachusetts, USA, revealed a strong and negative correlation between socioeconomic status and overall mental health. Glozah's [10] study found significant correlations between quality of social support and mental well-being, where socio-economic status played a moderating role. He studied the role of socioeconomic 
status, gender, the buffering role of social support and its impact on the psychological wellbeing of adolescents in Ghana. The socio-economically disadvantaged groups reported lower perceived social support compared to socioeconomically advantaged groups [10]. The results also confirmed that students from higher socioeconomic groups reported lower levels of academic stress. On the other hand, a meta-analysis of fifty-one studies showed that depression has stronger associations with socioeconomic status [19]. Some studies state that although socioeconomic status does have strong links with depression; it generates no significant differences in the scores for males and females [13]. Within socioeconomic status, it is implied that parents with lower education levels are often unable to provide a protective environment to their children, leaving them at greater risk for substance abuse and to develop depression in the future. Ibrahim et al's [13] study also found that when it comes to parent's education level, children with better educated mothers were at a 50\% lower risk for depression than those whose mothers had no higher education.

\title{
Rationale
}

The literature review indicates that mental well-being in terms of stress and depression is significantly impacted by perceived social support, family demands, differential gender treatment, field of education pursued and socio-economic status. However, very few studies have investigated mental well-being in the simultaneous presence of all these variables.

Cross cultural studies indicate that collectivist cultures rely on families as their primary source of social support. However, the moderating effect of socio-economic status of the support group is not frequently accounted for in these studies. In the context of our study, the city of Karachi is home to a socio-economically diverse population where family networks are considered an important source of social support. The diversity in socio-economic status may affect the quality, nature and perception of social support and family demands experienced by students here. Additionally, the patriarchal social structure that places emphasis on male achievement and dominance in the public sphere corroborates the importance of gender differences for mental well-being analyses.

Furthermore, claims regarding the more stressful lives of medical students are contentious since today's university life is taxing for many students regardless of their educational training. Many non-medical students are subject to significant stress as shown by Veena \& Shastri's study [28]. Since an increasing number of students are faced with demanding routines and future employment related insecurities in a highly competitive job market, educational background remains an important variable to consider when examining mental well-being.

The interconnectivity of the five selected variables makes a strong case for them to be examined concurrently in relation to student mental health.

\begin{abstract}
Aims
The aim of this study is to investigate the relationship perceived social support, family demands, gender, educational background and socio-economic status have with the mental well-being of undergraduate students in Karachi. The study intends to examine any significant associations each of the five variables have with the two components of mental well-being i.e. stress and depression levels. Furthermore, the study explores any significant associations the five variables may have with one another.
\end{abstract}

\section{KEY CONCEPTS}

For the purpose of this research, the following key variables are defined as: 
- Perceived Social Support is defined as the perception or actual experience that one is cared for or valued by others and that one is part of a social network that can be called upon in times of need [15].

- Family Demands are defined as the perceptions by students that their families unrealistically pin their hopes on them and burden them with requests and desires that they may not be able to fulfil [15].

- Mental Well-Being refers to psychological health indicated by low levels of depression and low levels of stress. Poor Mental Well-Being implies high scores on depression and stress [15].

- Socio-economic status (SES) refers to the combination of social status and economic status of the family [3]. Its main components include income, education and occupation [9].

- Educational Background refers to the type of academic training being received such as medicine, engineering and business.

\section{HYPOTHESES}

1. Ho: Perceived Social Support has a significant relationship with Mental Well-Being.

2. Ho: Perceived Social Support from family is significant for both males and females.

3. Ho: Males are more likely to experience stress than females.

4. Ho: Females are more likely to experience depression than males.

5. Ho: Family demands have a significant relationship with Mental Well-Being.

6. Ho: Male students are more likely to report higher Family Demands.

7. Ho: Socioeconomic status has a significant relationship with Mental Well-Being.

8. Ho: Students with low Socio-Economic Status shall report poor Mental Well-Being.

9. Ho: Educational Background has a significant relationship with Mental Well-Being.

10. Ho: Medicine students are most likely to show poor Mental Well-Being.

\section{Sample}

\section{METHODOLOGY}

The participants were 208 full time, undergraduate students from various universities in Karachi. 106 males and 102 females voluntarily participated in the completion of online questionnaires. All participants were aged between 16 and 26 years.

\section{Measures}

perceived social support. The construct of Perceived Social Support is assessed through the Multi-dimensional Scale of Perceived Social Support (MSPSS) that was introduced by Zimet, Dahlem, Zimet, \& Farley in 1988 [31]. The MSPSS includes sub-scales of support from family, friends and significant others. For the purposes of this research, only the family and friends sub-scales are used to assess social support in students.

mental well-being scales. Mental Well-Being is measured on the basis of two components; depression and stress. Depression is assessed via the eight-item Patient Health Questionnaire [17]. Respondents indicated their level of depression via a 4 point Likert scale that ranged from 0 (not at all) to 3 (nearly every day). Stress is measured through the 10-item Perceived Stress Scale [6] with answers ranging from Never to Very Often on a 5 point Likert scale.

family demands scale. Family Demands is measured through a scale developed by Netemeyer, Boles, and McMurrian in 1996 [21]. Items 6 to 10 were used to examine the effect of family life interfering with work life. 
socioeconomic status scale. The socio-economic status (SES) of the family is evaluated through an updated version of the original SES scale developed by Kuppuswamy \& BG Prasad [25]. Items included the education level of parents, their occupations and their monthly income.

\section{RESULTS}

Table 1: Correlations

\begin{tabular}{|c|c|c|c|c|c|c|c|c|}
\hline & & $\begin{array}{c}\text { PSS } \\
\text { Family }\end{array}$ & $\begin{array}{c}\text { PSS } \\
\text { Friends }\end{array}$ & $\begin{array}{c}\text { Family } \\
\text { Demands }\end{array}$ & SES & $\begin{array}{l}\text { Educational } \\
\text { Background }\end{array}$ & Depression & Stress \\
\hline \multirow{3}{*}{ PSS Family } & $\begin{array}{l}\text { Pearson } \\
\text { Correlation }\end{array}$ & 1 & $.399^{* *}$ & $-.267^{* *}$ & . 098 & $.143^{*}$ & $-.144^{*}$ & $236^{* *}$ \\
\hline & Sig. (2-tailed) & & .000 & .000 & 158 & .039 & .038 & .001 \\
\hline & $\mathrm{N}$ & 208 & 208 & 208 & 208 & 208 & 208 & 208 \\
\hline \multirow{2}{*}{ PSS Friends } & $\begin{array}{l}\text { Pearson } \\
\text { Correlation }\end{array}$ & $.399^{* *}$ & 1 & $-.346^{* *}$ & -.056 & .127 & $-.339^{* *}$ & -.070 \\
\hline & $\begin{array}{l}\text { Sig. (2-tailed) } \\
\mathrm{N}\end{array}$ & $\begin{array}{l}.000 \\
208\end{array}$ & 208 & $\begin{array}{l}.000 \\
208\end{array}$ & $\begin{array}{l}.419 \\
208\end{array}$ & $\begin{array}{l}.067 \\
208\end{array}$ & $\begin{array}{l}.000 \\
208\end{array}$ & $\begin{array}{l}.315 \\
208\end{array}$ \\
\hline \multirow{2}{*}{$\begin{array}{l}\text { Family } \\
\text { Demands }\end{array}$} & $\begin{array}{l}\text { Pearson } \\
\text { Correlation }\end{array}$ & $-.267^{* *}$ & $-.346^{* *}$ & 1 & -.026 & -.073 & $.427^{* *}$ & $.398^{* *}$ \\
\hline & Sig. (2-tailed) & .000 & .000 & & .708 & .295 & .000 & .000 \\
\hline \multirow{2}{*}{ SES } & $\begin{array}{l}\mathrm{N} \\
\text { Pearson } \\
\text { Correlation }\end{array}$ & $\begin{array}{l}208 \\
.098\end{array}$ & $\begin{array}{c}208 \\
-.056\end{array}$ & $\begin{array}{c}208 \\
-.026\end{array}$ & $\begin{array}{c}208 \\
1\end{array}$ & $\begin{array}{l}208 \\
.103\end{array}$ & $\begin{array}{c}208 \\
.277^{* *}\end{array}$ & $\begin{array}{l}208 \\
.176^{*}\end{array}$ \\
\hline & $\begin{array}{l}\text { Sig. (2-tailed) } \\
\mathrm{N}\end{array}$ & $\begin{array}{l}.158 \\
208\end{array}$ & $\begin{array}{l}.419 \\
208\end{array}$ & $\begin{array}{l}.708 \\
208\end{array}$ & 208 & $\begin{array}{l}.137 \\
208\end{array}$ & $\begin{array}{l}.000 \\
208\end{array}$ & $\begin{array}{l}.011 \\
208\end{array}$ \\
\hline \multirow{2}{*}{$\begin{array}{l}\text { Educational } \\
\text { Background }\end{array}$} & $\begin{array}{l}\text { Pearson } \\
\text { Correlation }\end{array}$ & $.143^{*}$ & 127 & -.073 & 103 & 1 & $.271^{* *}$ & 116 \\
\hline & Sig. (2-tailed) & .039 & .067 & .295 & .137 & סחק & .000 & .095 \\
\hline \multirow{3}{*}{ Depression } & $\begin{array}{l}\text { Pearson } \\
\text { Correlation }\end{array}$ & $-.144^{*}$ & $-.339^{* *}$ & $.427^{* *}$ & $.277^{* *}$ & $.271^{* *}$ & 1 & $.416^{* *}$ \\
\hline & Sig. (2-tailed) & .038 & .000 & .000 & .000 & .000 & & .000 \\
\hline & $\begin{array}{l}\mathrm{N} \\
\text { Pearcon }\end{array}$ & 208 & 208 & 208 & 208 & 208 & 208 & 208 \\
\hline \multirow{3}{*}{ Stress } & Correlation & $-.236^{* *}$ & -.070 & $.398^{* *}$ & $.176^{*}$ & .116 & $.416^{* *}$ & 1 \\
\hline & Sig. (2-tailed) & .001 & .315 & .000 & .011 & .095 & .000 & \\
\hline & $\mathrm{N}$ & 208 & 208 & 208 & 208 & 208 & 208 & 208 \\
\hline
\end{tabular}

**. Correlation is significant at the 0.01 level (2-tailed).

*. Correlation is significant at the 0.05 level (2-tailed).

In accordance with hypothesis 1, Pearson's coefficient correlation test indicated that there was a significant relationship between perceived social support and mental well-being. The two subsets of perceived social support i.e. family and friends were correlated with the two subsets of mental well-being i.e. stress and depression. The results showed that perceived support from family had a significant, negative correlation with both components of mental well-being i.e. depression $(r=-.144, N=208, p<0.01)$ and stress $(r=-.236, N=208, p<0.01)$. Perceived social support from friends had a statistically significant relationship with depression $(\mathrm{r}=$ $.339, \mathrm{~N}=208, \mathrm{p}<0.01$ ).

An Independent Samples T Test gave further insight to the role of perceived social support in relation to gender differences. Hypothesis 2 was not proven since males $(M=20.45, S D=3.22, t$ $(206)=6.92)$ were more likely to rely on friends for support than females did $(M=16.92, S D=$ 4.09). Although females observed greater support from their families $(M=15.46, S D=5.31)$ than males $(M=14.19, S D=4.34)$ did, the difference in mean scores was not statistically significant. Hypothesis 3 was not proven since there was no statistically significant difference 
in the scores on stress between the two genders. However, the test illustrated a significant difference in the scores for depression for males $(M=7.73, S D=6.09)$ and females $(M=14.37$, $\mathrm{SD}=6.45$ ) with a moderate effect size (eta squared $=0.06$ ). Therefore, hypothesis 4 was proven.

Hypothesis 5 was also proven since family demands had a moderately significant relationship with mental well-being at the $\mathrm{p}<0.01$ level $(\mathrm{r}=.491, \mathrm{~N}=208)$. Although, contrary to hypothesis 6 family demands were encountered more by females $(M=17.54, S D=4.84)$ than males $(M=14.92, S D=3.70)$.There was a significant positive correlation between socioeconomic status and mental well-being at the $\mathrm{p}<0.01$ level $(\mathrm{r}=.27, \mathrm{~N}=208)$ thus, hypothesis 7 was confirmed. Hypothesis 8 was not confirmed since the positive correlation indicates students from higher socioeconomic backgrounds as more likely to exhibit poor mental well-being. Socioeconomic status did not have a statistically significant relation with perceived social support, although it did have a moderate, negative correlation with family demands $(\mathrm{r}=-.026$, $\mathrm{N}=208, \mathrm{p}<0.01$ ).

Hypothesis 9 was proven since educational background had a significant correlation with mental well-being $(\mathrm{r}=.232, \mathrm{~N}=208, \mathrm{p}<0.01)$. The means plots graph in figure 8.1 shows participants divided into four broad categories in terms of the undergraduate degree they were pursuing i.e. Medicine, Engineering, Business and Other. The Other group included various miscellaneous educational backgrounds, though the most commonly reported degree in this category was Social Sciences. Both the means plot graphs (Fig 8.1, Fig 8.2) show the most

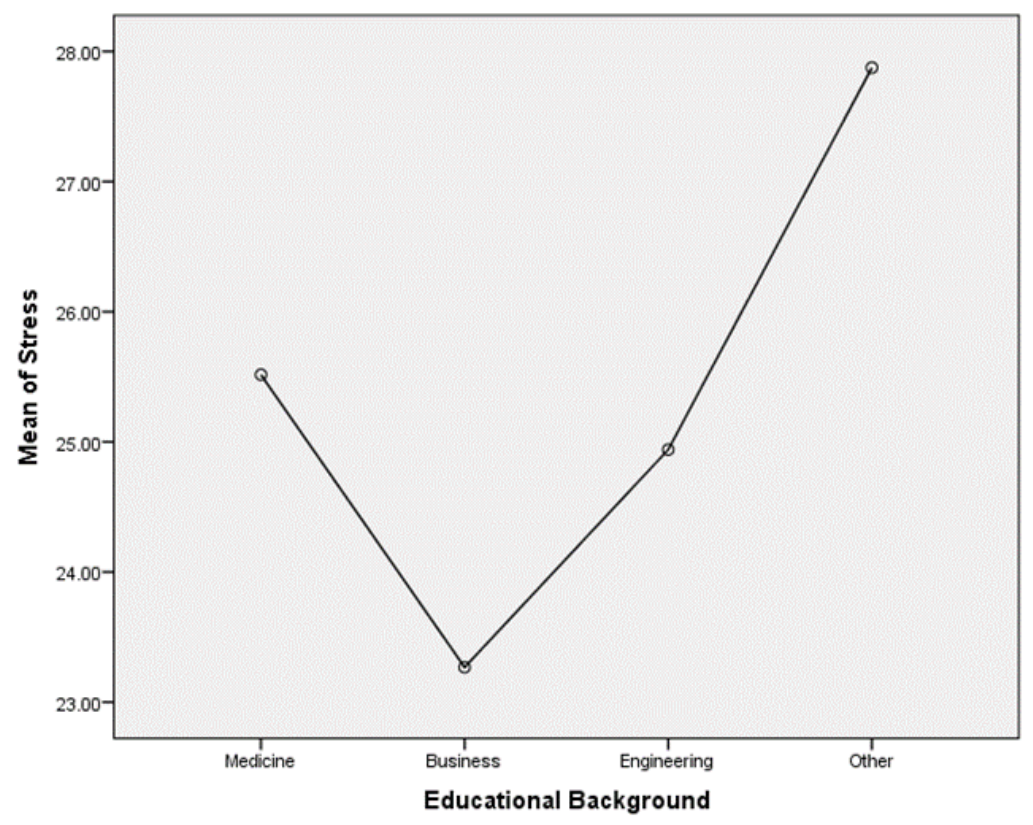

Figure 8.1 shows the mean stress levels experienced by students from different educational backgrounds

stress and depression experienced by the Other group. The trend was verified through a one way between groups analysis of variance. There was a statistically significant difference in stress scores at the $\mathrm{p}<0.5$ level between students from the Business $(M=23.26, S D=6.66)$ and Other ( $M=27.87, S D=6.91)$ educational backgrounds. However, the effect size calculated was small (eta squared $=0.05$ ). The difference in mean depression scores was statistically significant for all four groups at the $\mathrm{p}<0.5$ level. Post Hoc Analysis using the Tukey Test revealed that the three main educational groups greatly differed from the Other group's mean score. The lowest depression was reported by Medicine students ( $M=9.54, \mathrm{SD}=7.01)$ while the greatest depression was reported by students of the Other $(M=15.47, S D=6.71)$ educational background, thereby disproving hypothesis 10 . 


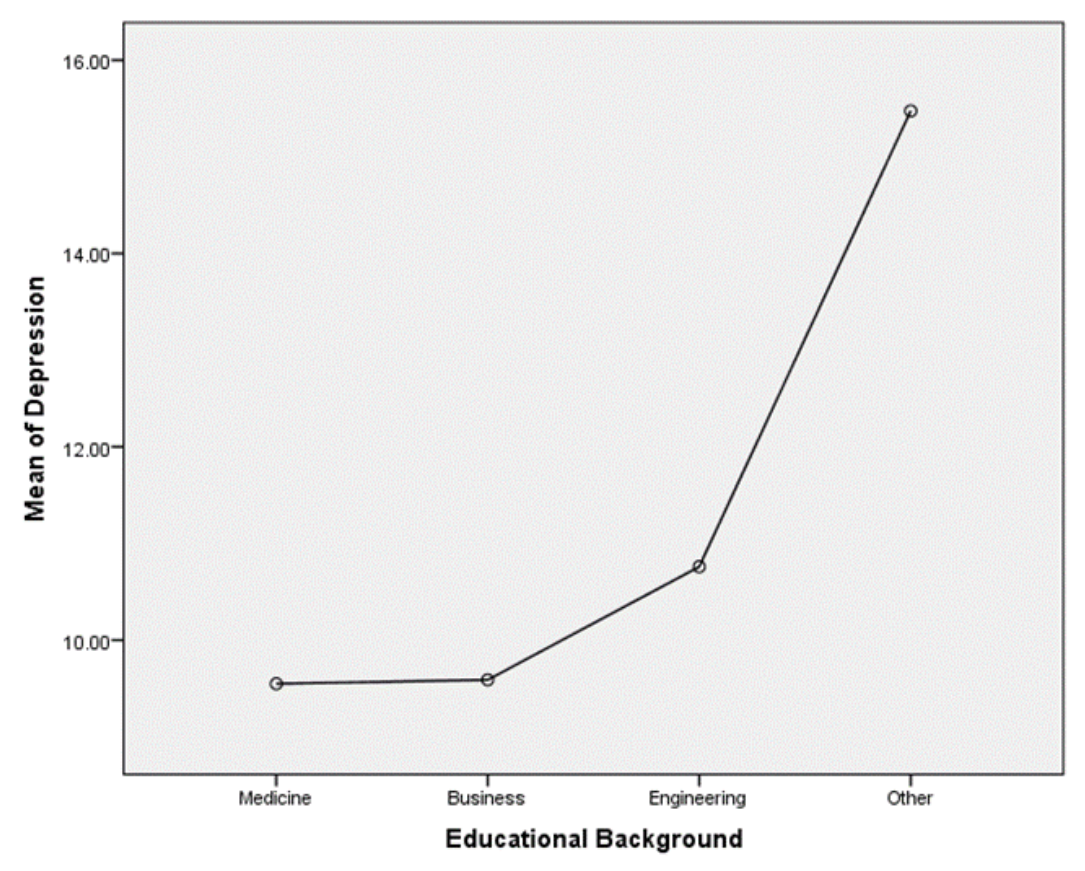

Figure 8.2 shows mean depression levels experienced by students of different educational backgrounds

\section{DISCUSSION}

The objective of the present study was to explore mental well-being's relationship with five variables; perceived social support, family demands, gender, socioeconomic status and educational backgrounds. Mental well-being comprised of two subcomponents; stress and depression. Low scores on stress and depression indicated positive mental well-being while higher scores on stress and depression suggested poor mental well-being. Further, the study aimed to highlight any significant inter-relationships among these selected variables. 10 hypotheses were tested to investigate the impact of each of these variables in a population of undergraduate students in Karachi.

The first hypothesis predicted that there shall be a significant relationship between the perception of social support and mental well-being. A Pearson coefficient correlation indicated that the relationship was significant and negative i.e. the greater scores in perceived social support result in lower scores for stress and depression, therefore indicating positive mental well-being. This negative correlation between perceived social support and mental well-being affirmed the findings of several studies such as those of [11, 24, 29].

Figure 1 illustrates that support from family is crucial for countering both stress and depression while support from friends is particularly linked with low depression scores. The second hypothesis predicted that support from family members would be more significant and valuable than support from friends for both the genders since our participants belong to a collectivist and family oriented society. However, this hypothesis was disproved as the independent $\mathrm{T}$ test clarified that males were more likely to seek out their friends for support. Females did perceive more support from family members compared to males but this result was not statistically significant. As posited by Asberg \& Bowers [2], males and females tend to develop distinct social support patterns. The result also added weight to Meithing et al's [20] argument that quality friendship networks are a crucial buffer against mental health problems during adolescence, especially when support from family is not available. It may also be argued that cultural differences allow for males to frequently network with their peers while females 
are often restricted mobility and are expected to be more family oriented, hence do not rely on their peers for much social support.

The independent $\mathrm{T}$ test did not confirm hypothesis 3 since males and females experienced similar levels of stress, implying that stress has little association with the independent variables of our study. This result confirms Kania's [16] research on gender differences related to stress. It may be argued that when given similar environmental inputs, males and females output similar levels of stress. On the other hand, hypothesis 4 was proven as males were significantly less depressed than females perhaps because they perceived greater social support from their friends. A Pearson correlation coefficient test confirmed hypothesis 5 as family demands had a significant association with mental well-being, particularly with the subset of depression. Inverse to the prediction of hypothesis 6 , females were more likely to report family demands than males. Thus, an emerging narrative from these results is that females experience more depression than males since they perceive greater demands from their families. Khallad and Jabr's [15] study bolsters support for this claim since they also found students who faced greater family demands as more depressed.

Hypothesis 7 correctly predicted that socioeconomic status has a significant relationship with mental well-being, as shown through a Pearson correlation coefficient test. However, the positive correlation indicated that hypothesis 8 was not confirmed because higher socioeconomic status implied higher scores for stress and depression i.e. poor mental wellbeing was reported by students from upper-middle classes. This result refuted findings from Hudson's and Glozah's study that saw a negative correlation between socioeconomic status and mental well-being $[12,10]$.

Hypothesis 9 was confirmed via a one way between groups analysis of variance test that showed a significant relationship between educational background and mental well-being. However, hypothesis 10 was disproven because medical students were least likely to experience depression. They also did not have significantly different stress scores from their counterparts which refuted the claims of Bukhari's [4] study that medical students experience greater stress than other students. As Veena \& Shastri's study indicates, students from other, non-medical educational backgrounds are equally likely to experience stress [28]. In our study, the most depression and stress was experienced by students from Other educational backgrounds, insinuating that restrictive, atypical and niche-based subjects take a toll on student mental health, perhaps because their novel experiences make them unrelatable to the general populace.

\section{STRENGTHS, LIMITATIONS AND IMPLICATIONS}

A major strength of this study is its simultaneous analysis of several variables known to have impacted mental well-being such as perceived social support, family demands, educational backgrounds and socioeconomic status. The study also assessed the broad construct of mental well-being in concrete terms through the two subsets of stress and depression. The findings from this research contribute to the scant literature on the mental health of students in Karachi. It also draws attention towards the psychological health of adolescents who, in many societies, are often the most misunderstood age group. Within the socio-cultural context of a collectivist society, the results of this study highlight the association family demands may have with depression. Future research may compare the effects of family demands with the lack of familial support as two distinct variables on the mental well-being of students. The present study also raises further questions regarding the link between social networking/friendship with depression and distinct educational experiences with mental well-being. 
As a primarily correlational study, the results of this research do not determine causality between the selected variables, hence any interpretation must keep this limitation in mind. A weakness of this study is the use of convenient sampling to administer online survey questionnaires therefore our sample may not be representative of the undergraduate student population of Karachi. A key limitation associated with self-report measures like questionnaires includes the possibility of withholding information or participant-response bias. For example, males may have felt uncomfortable reporting high scores on depression as it violates their image of male bravado. Future research may deploy other scientific methods of inquiry to confirm these trends regarding mental health for greater reliability. Further, the inclusion of an "other" category for educational backgrounds limits the interpretation of our results. Thus, future research may investigate mental health in students pursuing various nuanced educational programs that are often considered impractical career paths.

\section{CONCLUSION}

In summation, the results of this study reaffirm the importance of social support and family demands in shaping adolescent mental well-being. Parents and educators may want to be cautious of the demands and pressures they place on students, especially females. The study also extends current knowledge on the impact of socioeconomic status and educational backgrounds. It would be unfair to assume that the lives of students from privileged socioeconomic groups are necessarily better than those of lower socioeconomic groups. Students pursuing mainstream fields such as medicine, business and engineering may not feel as mentally strained as those who are studying novel subjects like in the Social Sciences. Further research may investigate the mental health and social contexts of such students who pursue atypical educational fields.

\section{References}

Al-Qaisay , L. (2011). The relation of depression and anxiety in academic achievement among group of university students. International Journal of Psychology and Counselling, 3(5), 96-100. Retrieved from http://www.academicjournals.org/IJPC

Asberg, K. K., \& Bowers, C. (2008). Stress and Psychological Adjustment in Adolescents: A Structural Equation Modeling Approach. PsycEXTRA Dataset. doi:10.1037/e528512007001

Baker, E. H. (2014). Socioeconomic Status, Definition. The Wiley Blackwell Encyclopedia of Health, Illness, Behavior, and Society, 2210-2214. doi:10.1002/9781118410868.wbehibs395

Bukhari, R. (2017). Perceived Social Support Predicts Psychological Problems among University Students. The International Journal of Indian Psychology, 4(2), 89th ser.

Chao, R. C. (2012). Managing Perceived Stress Among College Students: The Roles of Social Support and Dysfunctional Coping. Journal of College Counselling, 15(1), 5-21. doi:10.1002/j.2161-1882.2012.00002.x

Cohen, S., Kamarck, T., \& Mermelstein, R. (1983). Perceived Stress Scale. PsycTESTS Dataset. doi:10.1037/t02889000

Cuttilan , A., Sayampanathan, A., \& Ho, R. (2016). Mental health issues amongst medical students in Asia: a systematic review [2000-2015]. Annals of Translational Medicine, 4(4). doi:10.3978/j.issn.2305-5839.2016.02.07

Deb, S., Strodl, E., \& Sun, J. (2014). Academic-related stress among private secondary school students in India. Asian Education and Development Studies, 3(2), 118-134. doi:10.1108/aeds-02-2013-0007

El-Gilany, A., El-Wahady, A., \& El-Wasify, M. (2012). Updating and validation of the socioeconomic status scale for health research in Egypt. Eastern Mediterranean Health Journal, 18(9).

Glozah, F. N. (2013). Effects of Academic Stress and Perceived Social Support on the Psychological Wellbeing of Adolescents in Ghana. Open Journal of Medical Psychology, 02(04), 143-150. doi:10.4236/ojmp.2013.24022

Hamdan-Mansour, A. M., \& Dawani, H. A. (2007). Social Support and Stress Among University Students in Jordan. International Journal of Mental Health and Addiction, 6(3), 442-450. doi:10.1007/s11469-007-9112 
Hudson, C. G. (2005). Socioeconomic Status and Mental Illness: Tests of the Social Causation and Selection Hypotheses. American Journal of Orthopsychiatry, 75(1), 3-18. doi:10.1037/0002-9432.75.1.3

Ibrahim, A. K., Kelly, S. J., \& Glazebrook, C. (2013). Socioeconomic status and the risk of depression among UK higher education students. Social Psychiatry and Psychiatric Epidemiology, 48(9), 1491-1501. doi:10.1007/s00127-013-0663-5

Jibeen, T. (2015). Perceived Social Support and Mental Health Problems Among Pakistani University Students. Community Mental Health Journal, 52(8), 1004-1008. http://dx.doi.org/10.1007/s10597-015-9943-8

Khallad, Y., \& Jabr, F. (2015). Effects of perceived social support and family demands on college students' mental well-being: A cross-cultural investigation. International Journal of Psychology, 51(5), 348-355. doi:10.1002/ijop.12177

Kania, S. (2014). The Relationship Between Gender Differences and Stress. The Huron University College Journal of Learning and Motivation, 52(1). Retrieved from http://ir.lib.uwo.ca/hucjlm/vol52/iss1/7/

Kroenke, K., Strine, T. W., Spitzer, R. L., Williams, J. B., Berry, J. T., \& Mokdad, A. H. (2009). The PHQ-8 as a measure of current depression in the general population. Journal of Affective Disorders, 114(1-3), 163-173. doi:10.1016/j.jad.2008.06.026

Kumaraswamy, N. (2012). Academic Stress, Anxiety and Depression among College Students- A Brief Review. International Review of Social Sciences and Humanities , 5(1), 135-143.

Lorant, V. (2003). Socioeconomic Inequalities in Depression: A Meta-Analysis. American Journal of Epidemiology, 157(2), 98-112. doi:10.1093/aje/kwf182

Meithing, A., Almquist, Y., Östberg, V., Rostila, M., Edling, C., \& Rydgren, J. (2016). Friendship networks and psychological well-being from late adolescence to young adulthood: a gender-specific structural equation modeling approach. BMC Psychology, 4(1). http://dx.doi.org/10.1186/s40359-016-0143-2

Netemeyer, R. G., Boles, J. S., \& Mcmurrian, R. (1996). Work-Family Conflict Scale. PsycTESTS Dataset. doi: $10.1037 / \mathrm{t} 03587-000$

Park, K. H., Kim, D., Kim, S. K., Yi, Y. H., Jeong, J. H., Chae, J., . . Roh, H. (2015). The relationships between empathy, stress and social support among medical students. International Journal of Medical Education, 6, 103-108. doi:10.5116/ijme.0.

Ramezkhani, A., Z. G., Heyderabadi, A., Gilasi, H., \& Moosavi, S. (2013). Perceived social support, depression, and perceived stress in university students. Journal of Paramedical Sciences, 4(4).

Rehman, R., Habib, M., Fatima, S. S. (2014). A take on social wellbeing attributes by first year medical students. Journal of Pakistan Medical Association, 64(6), 679-682.

Shaikh, Z., \& Pathak, R. (2017). Revised Kuppuswamy and BG Prasad Socio economic Scales for 2016. International Journal of Community Medicine and Public Health,4(4). Retrieved from http://www.ijcmph.com/index.php/ijcmph/article/view/1242

Sokratous, S., Merkouris, A., Middleton, N., \& Karanikola, M. (2013). The association between stressful life events and depressive symptoms among Cypriot university students: a cross-sectional descriptive correlational study. BMC Public Health, 13(1). Doi: 10.1186/1471-2458-13-1121

Tam, C., Foo, Y., \& Lee, T. (2011). The Association between Perceived Social Support, Socio-economic Status and Mental Health in Young Malaysian Adults. East Asian Arch Psychiatry, 21(2).

Veena \& Shastri, S. (2016). Stress and Academic Performance. The International Journal of Indian Psychology , 3(3), 4th ser. Retrieved from http://www.ijip.in

Wang, X., Cai, L., Qian, J., \& Peng, J. (2014). Social support moderates stress effects on depression. International Journal of Mental Health Systems, 8(41).

Yu, Y., Yang, X., Yang, Y., Chen, L., Qiu, X., Qiao, Z., Bai, B. (2015). The Role of Family Environment in Depressive Symptoms among University Students: A Large Sample Survey in China. Plos One, 10(12). doi:10.1371/journal.pone.0143612

Zimet, G. D., Dahlem, N. W., Zimet, S. G., \& Farley, G. K. (1988). Multidimensional Survey of Perceived Social Support. PsycTESTS Dataset. Doi: 10.1037/t02380-000 